\title{
Investigation of micro-structure and mechanical properties of three steel alloys
}

\author{
Sujit Kumar Jha \\ Engineering Department, Ibra College of Technology \\ Ibra, Sultanate of Oman \\ Email: skj828@gmail.com \\ Tel: +968 25587936, Fax: +968 25549020
}

\begin{abstract}
The significant demands of steel in industrial applications and automotive and building industries are increasing. Thus, there is a need for the improvement of its mechanical properties by adding suitable alloy elements to them so that they have more strengthweight ratio. The objective of this research is to study the effect of adding various alloys to steel material and their effects on tensile and impact strengths, hardness, and microstructure. The tensile test was conducted on a round bar standard specimens of three kinds of steel having different compositions to investigate their mechanical properties. The results of tensile tests are given in tables, based on their stress-strain curves plotted to facilitate the design engineer to know the strength and accordingly design lightweight structures from this material. After the test, the microstructure of the fracture surface was observed using an inverted microscope. The tensile and impact strengths and hardness of carbon steel, EN 8 steel, and mild steel were evaluated and compared based on the chemical composition and microstructural observation. The experimental result showed that the increasing percentage of carbon and silicon in EN 8 steel increased its ultimate tensile and yielded strengths but reduced the percentage elongation compared to carbon steel. Similarly, less content of manganese with an increased content of nickel enhanced the impact strength of the mild steel but slightly reduced the tensile strength and hardness of mild steel compared to EN 8 steel.
\end{abstract}

Keywords: Steel alloy; mechanical properties; microstructure; fracture; strain rate.

\section{INTRODUCTION}

There is a high demand for steel members having the capacity to take more loads in less area; i.e., steels having more strength-weight ratio. For a design engineer, to use a material in thin sheet form, they must have accurate and reliable data of the tensile and impact strengths of the materials. The mechanical properties and microstructure of the steel materials vary with the addition to chemical composition and also by hot and cold forming processing. Generally, steel shows a yield point at the elastic limit. Ductility of steel is measured by elongation and reduction of area. Designer faces a challenge to select the optimal composition of steel material because an increase in the strength of steel alloys is always accompanied by a decrease in elongation. To avoid this, proper investigation of each constituent of the alloys in steel tested should be conducted to get the strength versus elongation values. The tensile test gives detail information on the steel alloys on strength and ductility during uniaxial applied loads. This information is vital for a design engineer to select proper materials under different circumstances used in industrial/construction 
applications. Steel is an alloy of iron and carbon with other alloy elements to improve mechanical properties. It is one of the most important engineering materials significantly used in industrial applications, building structures, automotive industries, and power plant engineering applications in the form of beams, rods, plates, tubes, and sheet metals. Depending on the percentage of carbon contents, steel can be classified as low carbon steel $(\% \mathrm{C}<0.3)$, medium carbon steel $(0.3<\% \mathrm{C}<0.6)$, eutectoid steel $(\% \mathrm{C}=0.8)$, and high carbon steel $(0.8<\% \mathrm{C}<1.2)$. These steels have been widely used to manufacture large diameter pipes for oil and gas transportation and in the form of heavy plates that can be used for naval ship construction [1]. The mechanical properties of metals and its alloys can be improved by a combination of metallurgical, manufacturing, and design measures, which increase the reliability and service life of the manufactured component [2]. The impact of tensile properties of $\mathrm{Cu}-\mathrm{Ni}$ alloy was investigated by using post-irradiation annealing and found to increase the annealing temperature and time yield strength as well as tensile strength [3]. An experiment was conducted on the fine-grained microstructure in copper and the test result was compared by applying uniaxial tension and compression force [4]. The production of low-cost steel is by reducing the content of $\mathrm{Co}, \mathrm{Mn}$, and $\mathrm{Cr}$ as well as investigating the impact of reduced alloys on mechanical properties and microstructure of steel [5]. The carbon content is important for providing a variety of strength and hardness by changing its composition in steel. The designer should have an idea of the modulus of elasticity, yield and ultimate tensile strengths, ductility and hardness of the material while designing a steel member for the industrial applications or structure members. The tensile, impact, and hardness tests give all the above details to designers to decide the failing criteria of the members during dynamic application of load on steel alloys. The alloys added to iron not only improve the mechanical properties but also enhance the anti-high temperature corrosion performance and oxidation resistance. For example, $\mathrm{Si}$ is added to improve oxidation resistance by forming a protective passive layer of $\mathrm{SiO}_{2}$ and also improves the mechanical properties at high temperature [6]. The research investigated the effect of $\mathrm{Ni}$ in addition to improve mechanical properties at room temperature [7]. This paper gave details on the effect of $\mathrm{Cr}$ addition to improve the resistance to high-temperature oxidation properties and also influence on the phase transformation and liquid temperatures [8]. The mechanical and electrical properties of the $\mathrm{Cu}-\mathrm{Ag}$ alloys have been studied during cold working operations and it was found that by adding a percentage of $\mathrm{Cr}$, tensile strength increases whereas electrical conductivity decreases [9]. A research investigated the microstructural behaviour and mechanical properties of copper and brass alloys by the tensile and impact tests and found that during dynamic loading, brass showed a high strength with reduced ductility [10].

The hardness of a material is the resistance to penetration of the surface by a hard indenter. The hardness of a material correlates with wear resistance, especially when manufacturing gear teeth in the transmission or the drive system of a vehicle requires harder material. Mild steel has definite yield point. It contains less than $0.3 \%$ carbon. Medium carbon steel contains $0.3 \%$ to $0.8 \%$ carbon. High carbon steel contains $0.8 \%$ to $1.2 \%$ carbon. As the carbon content increases the strength also increases but ductility is reduced. The high carbon steel does not show clear yield point. The modulus of elasticity (E) defines the properties of a material as it undergoes stress, deformations, and then returns to its original shape after the stress is removed. It is a measure of the stiffness of a given material. The yield strength is the stress at the point in the stress-strain curve, where plastic deformation is noticeable. The ultimate tensile strength is the stress at the highest applied force at which necking begins and requires a lower force to continue further deformation in ductile materials. Ductility is the amount of deformation material that can withstand without breaking and has significant factors for designers and 
manufacturers, especially considering forming operations like rolling and extrusion. The elongation value during the test also depends on the gage length. The smaller the gage length the higher the localised strain in the necked region. According to Arlazarov et al., austenite grain size can be reduced by cold rolling after double annealing to a $0.092 \% \mathrm{C}$ $4.6 \% \mathrm{Mn} \mathrm{wt} \%$ steel to investigate the mechanical properties and microstructure as a function of inter-critical annealing time with Mn segregation. They found that true stress is directly linked to holding temperature and time [11]. Saleh et al. [12] investigated the mechanical properties of composite materials by the tensile, impact, and creep tests and found that $\mathrm{CKCF}$ carbon composites have better mechanical properties in comparison of CRCF and CYCF carbon composites. Hariprasad et al. [13] investigated the tensile and impact strengths of an alkali-treated banana-coir epoxy hybrid composite and found that tensile and impact strengths are more than untreated banana-coir epoxy hybrid composite, whereas the flexural strength of the untreated banana-coir epoxy hybrid composite was more. The content of manganese is usually limited to reduce solidification segregation and by combining with Sulphur that reduces the chance of solidification cracking. Similarly, the content of nickel improves the toughness and adds a solid solution hardening effect [14]. The increased content of chromium enhances the tensile strength and hardness of the steel alloys, which further increase by the larger impact of manganese at low concentrations [15]. The research found that optimum content of Si in T91 grade steel provides desired impact strength after an investigation within temperature region 40 to $440{ }^{\circ} \mathrm{C}$ using the Charpy Method [16].

The main objective of this research is to investigate the changes in mechanical properties of the steel alloys as a result of variation in the composition of the alloying elements. The tensile and impact strengths and hardness of carbon steel, EN 8 steel, and mild steel alloys were investigated with the variation composition of $3 \mathrm{C}, 3 \mathrm{Mn}, 3 \mathrm{Si}, 3 \mathrm{P}$, $2 \mathrm{Cr}$, and $2 \mathrm{Ni}$ percentage present in the steel alloys. This research also investigated the microstructural behaviour of steel alloys using an inverted microscope. This article is organised as follows; Section 2 illustrates test materials and experimental methods. Results and discussions are presented in detail in Section 3, while Section 4 gives the concluding remarks.

\section{METHODS AND MATERIALS}

This research considered steel alloys to study the impact of alloys addition on mechanical properties of the material. The chemical compositions of the alloys are shown in Table 1. Annealing is the heat treatment process to improve the mechanical properties and microstructure of steels by refining its grain due to ferrite-pearlite microstructure [17]. The impact of heat treatment on microstructure and mechanical properties of martensitic steel was studied and hardness and toughness of steel were found to retain around 61.6 $\mathrm{HRC}$ and $20 \mathrm{~J}$ due to the high carbon martensite and fine grain size when quenched up to $1100{ }^{\circ} \mathrm{C}$ [18]. The impact of isothermal tempering on the microstructure and mechanical properties of high Co-Ni secondary hardening ultrahigh strength steel was analysed and steel was found to retain the tensile strength of value $2222 \mathrm{MPa}$ and a hardness value of 56.5 HRC with prolonged tempering time although toughness reduced with the increase of tempering time [19]. According to Mathew and Rajendra Kumar, the Taguchi-Grey method was applied to investigate the effect of boronisation process parameters on tensile properties of low carbon steel and carburised carbon steel. They found that ultimate tensile strength is influenced by the boronising temperature more than process time and carbon content [20]. 
Table 1. Chemical compositions of the steel used.

\begin{tabular}{lcccccccc}
\hline Alloy Names & $\mathrm{C}$ & $\mathrm{Mn}$ & $\mathrm{Si}$ & $\mathrm{S}$ & $\mathrm{P}$ & $\mathrm{Cr}$ & $\mathrm{Ni}$ & $\mathrm{Fe}$ \\
\hline Carbon Steel & 0.12 & 0.980 & 0.05 & 0.28 & 0.05 & & & Balance \\
EN-8 Steel & 0.452 & 0.780 & 0.230 & 0.011 & 0.024 & 0.010 & 0.001 & Balance \\
Mild Steel & 0.182 & 0.717 & 0.228 & 0.010 & 0.031 & 0.007 & 0.002 & Balance \\
\hline
\end{tabular}

To investigate the mechanical properties of steel, standard test procedures were considered by using standard test specimens. Specimens of each material were tested at room temperature on GUNT Universal Testing Machine (UTM) with constant crosshead movement of $2 \mathrm{~mm} / \mathrm{min}$ for the tensile strength of the material [21]. An extensometer was used to calibrate and measure the sample strain upon loading. Tensile tests were performed at room temperature on a cylindrical specimen with a gauge length of $30 \mathrm{~mm}$ with $6 \mathrm{~mm}$ diameter for carbon steel and $5.7 \mathrm{~mm}$ diameter for mild steel specimen, whereas for EN 8 steel alloy the gauge diameter and lengths were $5.8 \mathrm{~mm}$ and $33 \mathrm{~mm}$, respectively. The tests were run under constant and continuous application of load at an initial strain rate of $1.3 \times 10^{-4} \mathrm{~s}^{-1}$ for all steel alloys on a GUNT Universal Tensile Machine (UTM). The specimens were loaded continuously until failure. The impact test was carried out on GUNT pendulum impact tester of $300 \mathrm{Nm}$ maximum capacity for a specimen dimension of $55 \times 10 \times 10 \mathrm{~mm}$ in length, width, and height. The microstructure of the fracture surface of the specimen after the tensile and impact tests was examined using an inverted microscope after polishing it using nital etchant $2 \% \mathrm{HNO}_{3}$ and $98 \%$ ethanol for all three steel alloys for 15 seconds. Rockwell hardness test was carried out on each specimen using the universal hardness testing machine in F scale with 1/16 in. steel ball indenter and $100 \mathrm{Kg}$ applied load. The mechanical properties of AA 6060 and 6061 were observed during experimental analysis by varying compositions of $\mathrm{Mg}$ alloy to the aluminium alloy tested [21]. An experiment was conducted on welded joint and the weld current nugget increased with the increasing diameter and further increased the loading force. However, by increasing electrode pressure the applied force value will decrease during tensile test [22]. An experimental analysis was conducted on $\mathrm{Cu}$ and brass alloys to observe the mechanical properties by varying their compositions on tensile strength [23]. The grain refinement caused by the alloying elements $\mathrm{Fe}-18 \mathrm{Cr}-16 \mathrm{Ni}$ is the source for the decrease in elongation whereas increase in tensile strength [24]. The addition of $\mathrm{Cr}$ improved the tensile strength similarly by addition of $\mathrm{Ni}$ that improved the tensile strength but also delayed delamination associated with strain [25]. The addition of Mn content into alloys does better grain refinement process that has a littleimproved elongation than the Mn-free alloys. Similarly, the deviation of tensile strength is unequal and by the addition of $\mathrm{Mn}$, the content alloys have higher ultimate tensile strength than the Mn-free alloy [26].

The tensile test is used to determine the tensile strength of a material and also measure the elongation at fracture. During the test, the specimen was fixed in the grip holder of the testing machine in such a way that the load can be applied axially and a single-axis stress state has been generated to the specimen in a longitudinal direction. This results in a uniform normal distribution of stress across the test cross-section of the specimen. Bearing the load indicates pointer of the dial to zero and applied the load slowly and continuously by turning the hand wheel until it breaks. The resulting maximum test force is a measure of the material's strength called ultimate tensile strength $R_{m}$ in N/mm calculated from the maximum test force $F_{B}$ in $N$, determined from the force-elongation diagram and the initial cross-section $\mathrm{A}_{0}$ of the specimen in $\mathrm{mm}^{2}$. The elongation at fracture is the change ratio in length of the specimen to its original length $\mathrm{L}_{0}$ and 
calculated by measuring the length $\mathrm{L}_{\mathrm{u}}$ of the specimen after fracture. The result of the tensile test has been represented in a stress-elongation diagram. From the graph, the ultimate tensile strength $R_{m}$, proportionality limits $R_{p}$, yielding point $R_{e}$, and fracture strength $\mathrm{R}_{\mathrm{f}}$ were calculated and reported in Tables 2-4 for all three specimens. Generally, hardened steel virtually ruptures without plastic deformation but has high tensile strength, tempered steel is far tougher but still has a high strength, while the soft annealed steel has a very high elongation but a low tensile strength.
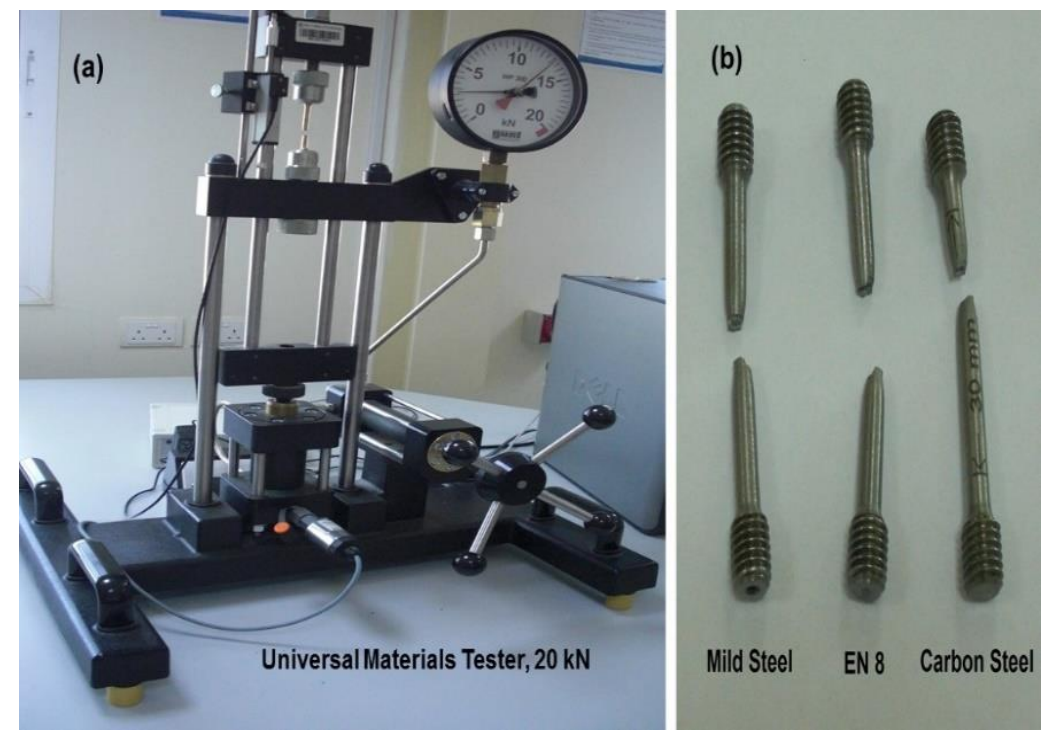

Figure 1. (a) Universal Testing Machine (UTM) and (b) specimen after fracture.

\section{Tensile Test}

The tensile test is a standard test conducted on GUNT universal testing machine with standard test specimens. From the literature survey, it was found that many varieties of tensile specimens with different dimensions have been used by different authors based on the availability of materials. In many cases, the specimen's dimensions were other than dictated by ASTM. They have investigated the impacts of specimen size and geometry on the tensile strength of pure ultra-fine-grained copper [27]. The tensile property of two materials has been investigated and the impacts of changing the gage length on mechanical properties observed [28]. This research considered the standard specimens for steel material to find tensile strength of the materials. Three test pieces of each material like carbon steel, EN 8 steel, and mild steel have been used for determining the tensile strength of all materials on UTM. The mechanical behaviour of each specimen was determined from the tensile test data of the specimen. A diameter of $6 \mathrm{~mm}$ and $30 \mathrm{~mm}$ gauge length (L/D ratio is 5) with $64 \mathrm{~mm}$ of total length for carbon steel, $5.7 \mathrm{~mm}$ gauge diameter, gauge length of $30 \mathrm{~mm}$ for mild steel alloys, and a specimen for gauge diameter $5.8 \mathrm{~mm}$ and gauge length of $33 \mathrm{~mm}$ with total length of $67 \mathrm{~mm}$ for EN 8 steel alloys were used for the experimental analysis. Researchers did experimental analysis on $\mathrm{Cu}, \mathrm{Al}, \mathrm{Au}$, and $\mathrm{Ni}$ foils with a thickness less than $250 \mu \mathrm{m}$ and it has been observed that yield strength increased while tensile strength decreased by the decreasing thickness of foil $[29,30]$. Figure 1 shows the experimental setup for tensile test on UTM of each specimen and fractured specimens after the test.

The tensile test was carried on UTM of $20 \mathrm{KN}$ capacity at across head speed of 2 $\mathrm{mm} / \mathrm{min}$, where the load-deflection curve was obtained for each specimen. Data were generated during the test like applied load, elongation, stress and percentage elongation 
in the table and graphs and curves were plotted for each specimen by continuous application of load until fracture. After the test, the yield, tensile, and fracture strengths, and ductility were measured while the fracture surfaces were examined using an inverted microscope. From the literature survey and experimental observation, it was found that tensile properties of specimens were dependent on the annealing temperature as well as time by increasing, reducing and ductility improving any tensile strength normally. From the tensile test data generated, it was observed that the tensile properties changed with annealing temperatures. It was determined that carbon steel and EN 8 sheet of steels showed continuous yielding behaviour whereas mild steel showed discontinuous yielding. According to Fang et al., steels showing continuous yield have proven stress at $0.2 \%$ strain called yield strength while ferrite-martensite steels showing discontinuous yield was due to high dislocation density surrounding the martensite islands [31].

\section{Carbon Steel (S9Mn28)}

Gauge length $\left(l_{0}\right)=30 \mathrm{~mm}$, gauge diameter $\left(\mathrm{d}_{0}\right)=6 \mathrm{~mm}$ and increased length $\left(1_{\mathrm{u}}\right)=42$ $\mathrm{mm}$ reduced diameter $\left(\mathrm{d}_{\mathrm{f}}\right)=4.3 \mathrm{~mm}$. Data collected during the tensile test are shown in Table 2. Figure 2 shows the increase in length after the failure of the specimen in the tensile test while Figure 3 shows the stress-percentage elongation graph in software supporting the tensile test.

Table 2. Tensile Test result for carbon steel material

\begin{tabular}{cccccc}
\hline $\begin{array}{c}\text { S. } \\
\text { No. }\end{array}$ & $\begin{array}{c}\text { Load } \\
\mathrm{P}(\mathrm{N})\end{array}$ & $\begin{array}{c}\text { Elongation } \\
\mathrm{e}(\mathrm{mm})\end{array}$ & $\begin{array}{c}\text { Stress } \\
\sigma=\frac{P}{A_{0}}\left(\mathrm{~N} / \mathrm{mm}^{2}\right)\end{array}$ & $\begin{array}{c}\text { \% Elongation } \\
E P S=\frac{e}{l_{0}} \times 100\end{array}$ & $\begin{array}{c}\text { Stress at Yield Point, } \\
\text { Maximum load, Break } \\
\text { point. }\left(\mathrm{N} / \mathrm{mm}^{2}\right)\end{array}$ \\
\hline 1 & & & 4.747 & 0.081 & \\
2 & 1.812 & 0.106 & 64.134 & 0.354 & \\
3 & 7.430 & 0.391 & 262.791 & 1.302 & Young Modulus = 263 \\
4 & 8.484 & 0.373 & 300.220 & 1.245 & \\
5 & 9.424 & 0.439 & 333.321 & 1.465 & Upper Yield $=333$ \\
6 & 8.111 & 0.757 & 286.866 & 2.523 & Lower Yield $=287$ \\
7 & 8.168 & 1.538 & 288.900 & 5.127 & \\
8 & 10.259 & 2.808 & 362.821 & 9.359 & \\
9 & 11.045 & 3.979 & 390.626 & 13.265 & \\
10 & 11.534 & 5.151 & 407.919 & 17.171 & \\
11 & 11.812 & 6.909 & 417.753 & 23.031 & \\
12 & 11.869 & 7.764 & 419.787 & 25.879 & Maximum Stress = 420 \\
13 & 11.534 & 9.790 & 407.919 & 32.633 & \\
14 & 10.594 & 10.791 & 374.689 & 35.970 & \\
15 & 9.511 & 11.377 & 336.372 & 37.923 & Fracture Stress = 336 \\
\hline
\end{tabular}

$A_{o}=\frac{\pi}{4} d_{i}^{2}=\frac{\pi}{4}(6)^{2}=28.26 \mathrm{~mm}^{2}, \quad A_{f}=\frac{\pi}{4} d_{f}^{2}=\frac{\pi}{4}(4.3)^{2}=14.51 \mathrm{~mm}^{2}$

$\operatorname{Strain}(\varepsilon)=\frac{l_{u}-l_{o}}{l_{o}}=\frac{42.0-30.0}{30.0}=0.40, \quad \%$ reduction in area $=\frac{A_{o}-A_{f}}{A_{o}} \times 100=48.66$ 

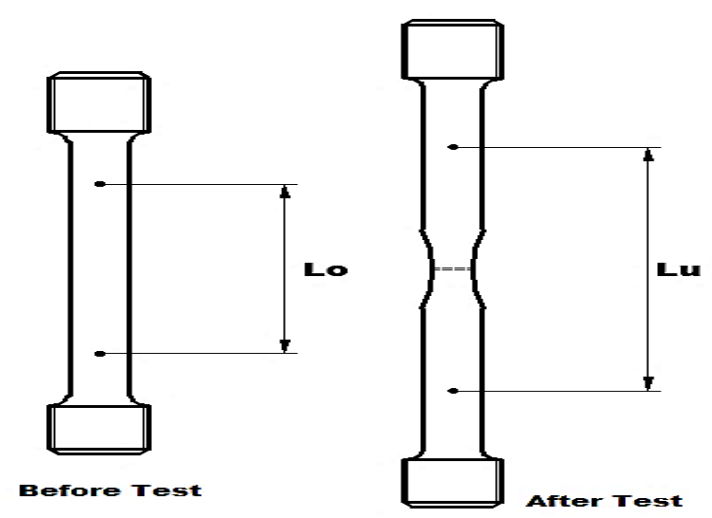

Figure 2. The change in length of a specimen after fracture.

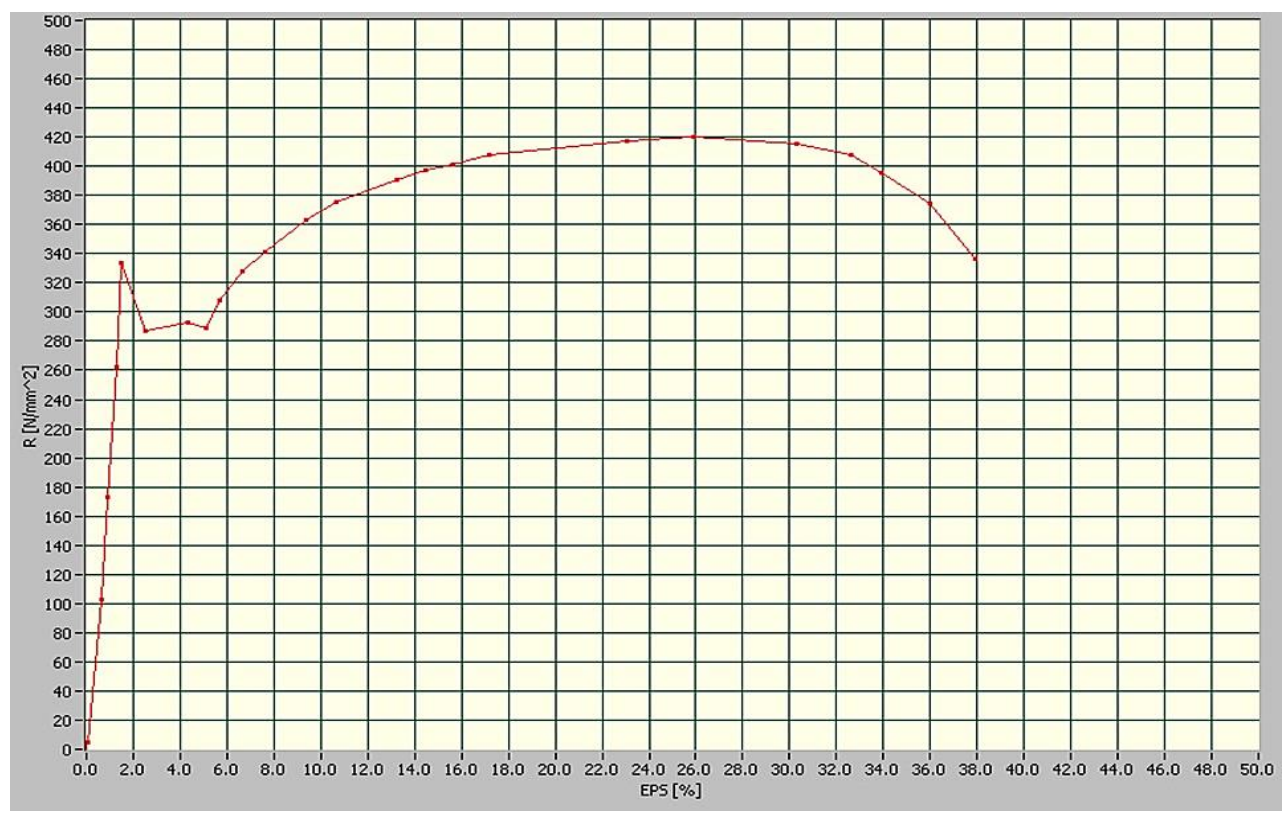

Figure 3. Stress-Strain curve for carbon steel.

Mild Carbon Steel (EN-8): Gauge length $\left(1_{0}\right)=30 \mathrm{~mm}$, gauge diameter $\left(\mathrm{d}_{0}\right)=5.8 \mathrm{~mm}$ and increased length $\left(l_{\mathrm{u}}\right)=34.7 \mathrm{~mm}$ reduced diameter $\left(\mathrm{d}_{\mathrm{f}}\right)=4.7 \mathrm{~mm}$. Data collected during the tensile test are shown in Table 3.

Mild Steel: Gauge length $\left(1_{0}\right)=30 \mathrm{~mm}$, gauge diameter $\left(\mathrm{d}_{0}\right)=5.7 \mathrm{~mm}$ and increased length $\left(l_{\mathrm{u}}\right)=34.0 \mathrm{~mm}$ reduced diameter $\left(\mathrm{d}_{\mathrm{f}}\right)=4.5 \mathrm{~mm}$. Data collected during the tensile test are shown in Table 4.

\section{Hardness}

The hardness of the steel specimen is indicated by the depth of penetration of the steel ball indenter on the specimen. The hardness of material imparts the most important properties for determining the strength and resistance to wear and scratching of the surface of the material. The hardness of a material can be defined as the ability of a material to resist indentation or deformation marked on the surface with an indenter under load. The Rockwell hardness of materials was determined using steel ball of 1/16" diameter and $100 \mathrm{Kgf}$ applied load in scale B. The hardness value was displayed directly on the LCD screen of the universal hardness machine. The Rockwell hardness was 
measured on the surface at five different locations and then the values were averaged and noted for each specimen. The hardness of carbon steel was $68.8 \mathrm{HRB}$, EN 8 steel was 88.5 HRB, and mild steel was $84.18 \mathrm{HRB}$. The hardness of steel alloys varied due to the presence of $\mathrm{Sn}, \mathrm{Fe}$, and $\mathrm{Zn}$ content.

Table 3. Tensile test result for EN 8 steel material.

\begin{tabular}{|c|c|c|c|c|c|}
\hline $\begin{array}{l}\text { S. } \\
\text { No. }\end{array}$ & $\begin{array}{l}\text { Load } \\
\text { P (N) }\end{array}$ & $\begin{array}{c}\text { Elongation } \\
\text { e (mm) }\end{array}$ & $\begin{array}{c}\text { Stress } \\
\sigma=\frac{P}{A_{0}}\left(N / \mathrm{mm}^{2}\right)\end{array}$ & $\begin{array}{l}\% \text { Elongation } \\
E P S=\frac{e}{l_{0}} \times 100\end{array}$ & $\begin{array}{l}\text { Yield Stress, Maximum } \\
\text { load, Break point. } \\
\left(\mathrm{N} / \mathrm{mm}^{2}\right)\end{array}$ \\
\hline 1 & 0.211 & 0.024 & 7.460 & 0.081 & \\
\hline 2 & 3.288 & 0.122 & 116.306 & 0.407 & \\
\hline 3 & 6.523 & 0.203 & 246.989 & 0.678 & \\
\hline 4 & 11.217 & 0.415 & 396.729 & 1.383 & \\
\hline 5 & 15.177 & 0.562 & 536.772 & 1.872 & Young Modulus = 537 \\
\hline 6 & 17.948 & 0.684 & 634.767 & 2.279 & Yield Stress $=635$ \\
\hline 7 & 21.179 & 0.928 & 749.039 & 3.092 & \\
\hline 8 & 22.339 & 1.123 & 790.068 & 3.743 & \\
\hline 9 & 24.247 & 1.685 & 857.546 & 5.615 & \\
\hline 10 & 24.851 & 2.100 & 878.908 & 6.999 & \\
\hline 11 & 24.946 & 2.539 & 882.299 & 8.464 & Maximum Stress $=882$ \\
\hline 12 & 24.170 & 2.979 & 854.833 & 9.928 & \\
\hline 13 & 22.492 & 3.760 & 795.493 & 12.533 & \\
\hline 14 & 20.594 & 4.175 & 728.355 & 13.916 & Fracture Stress $=728$ \\
\hline
\end{tabular}

Table 4. Tensile Test result for mild steel material.

\begin{tabular}{|c|c|c|c|c|c|}
\hline $\begin{array}{l}\text { S. } \\
\text { No. }\end{array}$ & $\begin{array}{l}\text { Load } \\
P(N)\end{array}$ & $\begin{array}{c}\text { Elongation } \\
\text { e (mm) }\end{array}$ & $\begin{array}{c}\text { Stress } \\
\sigma=\frac{P}{A_{0}}\left(N / m^{2}\right)\end{array}$ & $\begin{array}{l}\text { \% Elongation } \\
E P S=\frac{e}{l_{0}} \times 100\end{array}$ & $\begin{array}{l}\text { Stress at Yield Point, } \\
\text { Maximum load, Break } \\
\text { point. }\left(\mathrm{N} / \mathrm{mm}^{2}\right)\end{array}$ \\
\hline 1 & 1.467 & 0.000 & 51.880 & 0.000 & \\
\hline 2 & 5.906 & 0.000 & 208.876 & 0.000 & \\
\hline 3 & 15.532 & 0.000 & 549.318 & 0.000 & Young Modulus $=549$ \\
\hline 4 & 17.315 & 0.000 & 612.387 & 0.000 & Upper Yield Stress $=612$ \\
\hline 5 & 18.331 & 0.000 & 648.331 & 0.000 & \\
\hline 6 & 18.839 & 0.000 & 666.302 & 0.000 & Maximum Stress $=666$ \\
\hline 7 & 18.360 & 0.000 & 649.348 & 0.000 & \\
\hline 8 & 10.805 & 0.049 & 382.149 & 0.163 & Lower Yield Stress $=382$ \\
\hline 9 & 17.353 & 0.195 & 613.744 & 0.651 & \\
\hline 10 & 17.219 & 0.342 & 608.997 & 1.139 & \\
\hline 11 & 15.551 & 1.025 & 549.996 & 3.418 & \\
\hline 12 & 14.266 & 1.440 & 504.558 & 4.801 & Fracture Stress $=504$ \\
\hline
\end{tabular}




\section{Impact Test}

The impact strength is the measure of the energy absorbed by the standard specimen when it fails while being struck with a hammer. The impact strength of a material can also be defined as equal to the work performed in breaking a specimen during impact test and also related to the toughness of the material. The toughness of the material is to absorb energy during the plastic deformation when subjected to suddenly applied loads. Due to small plastic deformation before failure, the brittle material has low toughness, whereas ductile material has more resistance to suddenly applied load as it can absorb considerable energy before failure. The impact test is normally used to find the safe condition of structural members during industrial and building applications. The specimen with the notch is tested in impact test so that the specimen fails at the notch under a single blow of hammer and at less energy compared to without notch specimen. The energy required to break the specimen is a measure of impact strength. The impact strength of carbon steel, EN 8 steel, and mild steel alloys was tested on pendulum impact testing machine with capacity $150 \mathrm{~J}$ and can be increased to $300 \mathrm{~J}$ at room temperature. Each specimen is a square rod $10 \mathrm{~mm} \times 10 \mathrm{~mm} \times 55 \mathrm{~mm}$ length with a V-notch of $27.5 \mathrm{~mm}$ from one end. The depth of notch was $2 \mathrm{~mm}$ and internal angle of $\mathrm{V}$ was $45^{\circ}$ with a root radius of $0.25 \mathrm{~mm}$ and kept on the anvil to support the test. The energy absorbed by the specimen during fracturing was computed by the initial energy of the hammer before striking minus the final energy remaining in the hammer after it broke the specimen. The absorbed energy $(E)=m \times g \times\left(h_{1}-h_{2}\right)$ joule was displayed in software installed for supporting the test on pendulum impact testing machine to generate data associated with the test, where $\mathrm{m}$ is the mass of the hammer, $\mathrm{g}$ is the gravitational acceleration, $\mathrm{h}$ is the height of the hammer before striking and $h_{1}$ is the maximum height after fracturing the specimen.

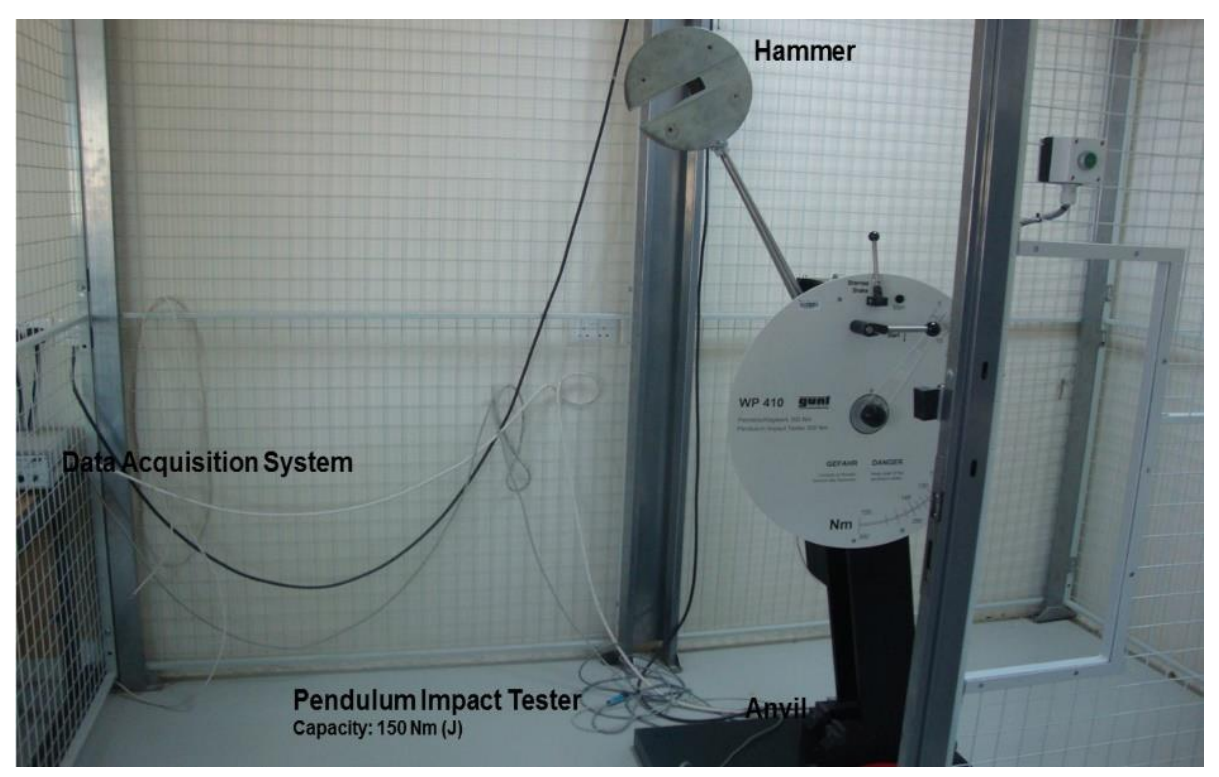

Figure 4. Equipment used for impact test.

The impact strength of the material depends on the lattice type of materials, test temperature, chemical composition of materials, and degree of strain hardening. Figure 4 shows the experimental setup used during the experiment to find the impact strength and finally the fracture surface of the specimen microstructure was observed using an inverted microscope. From the experimental observation, it was observed that the impact strength 
of carbon steel was $36.50 \mathrm{~J} / \mathrm{cm}^{2}$, whereas that of EN8 steel was $51.75 \mathrm{~J} / \mathrm{cm}^{2}$ and mild steel was $125 \mathrm{~J} / \mathrm{cm}^{2}$.

\section{RESULTS AND DISCUSSION}

The chemical compositions of three steel materials, their mechanical properties after the experimental performance on standard specimen and microstructure of the fracture surface were studied. The results of the analysis are discussed in the following sections.

\section{Metallographic Analyses}

The microstructure of steel alloys has more influence on the steel mechanical properties. After the tensile and impact tests, the fractured specimens were neatly cleaned and abraded with $\mathrm{SiC}$ paper, polished with $1-\mu \mathrm{m} \mathrm{Al}_{2} \mathrm{O}_{3}$ powder, washed with distilled water, and finally etched with $5-10 \%$ natal solution for microscopic observation. The fracture surfaces were examined using an inverted microscope provided with internal ISO camera and power supply of $6 \mathrm{~V} / 30 \mathrm{~W}$ halogen bulbs. The camera captured the image while window graphically displayed the frequency distribution of colour values in line view. Figure 5 shows the microstructure of fracture surface after tensile test of carbon steel alloys, EN-8 steel alloys, and mild steel alloys. The microstructure was observed by an inverted microscope of the specimen after fracture and the iron dendrites were identified surrounded by carbon and manganese alloys in grey phase. Figure 6 shows the microstructure of fracture surface after impact test of carbon steel alloys, EN-8 steel alloys, and mild steel alloys.
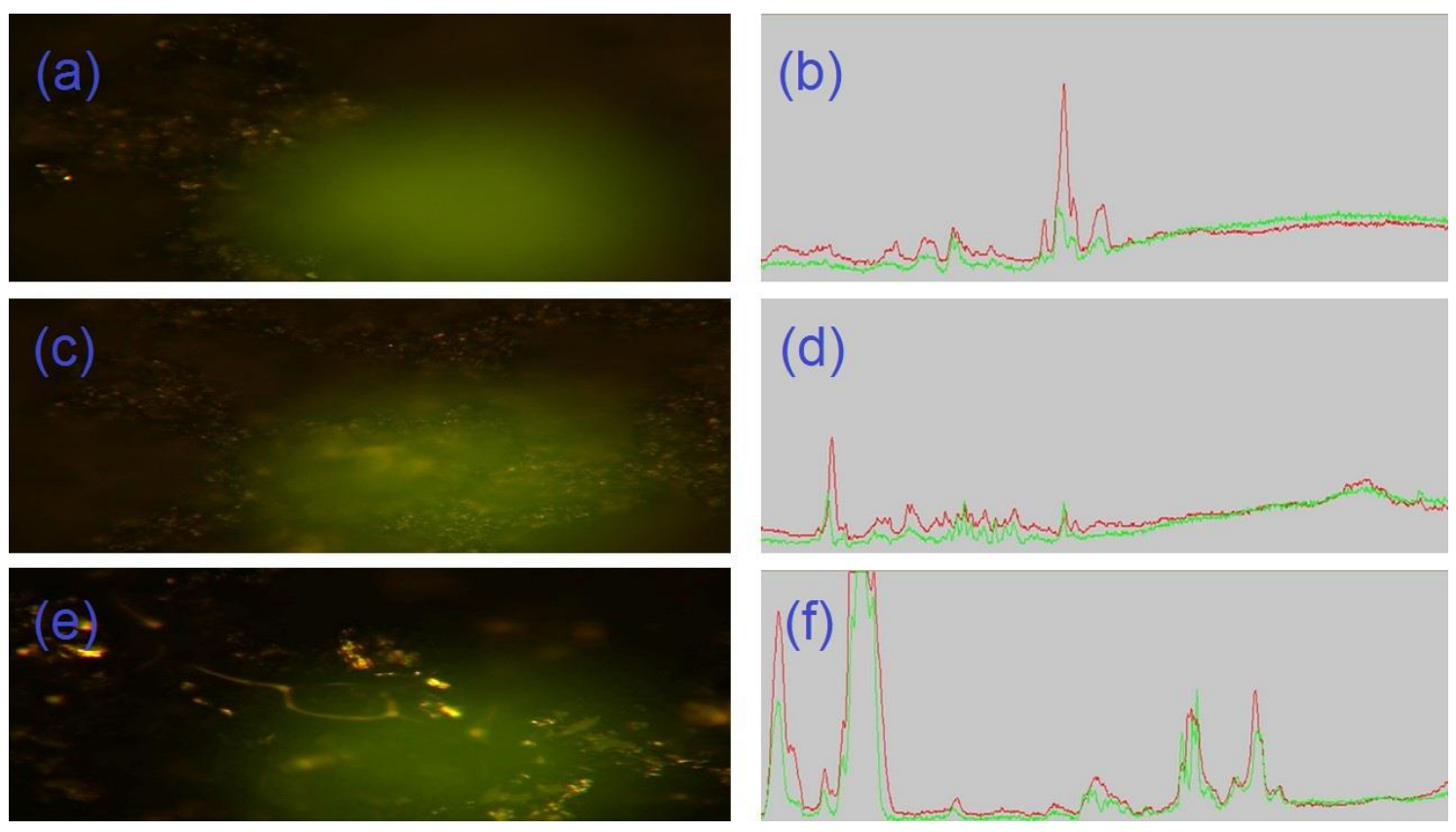

Figure 5. Typical microstructure of steel alloys after tensile test at Mag. 20X: (a) shows the microstructure of carbon steel, (b) shows the colour value variation in a frequency line, (c) shows the microstructure of EN 8, (d) shows the colour value variation in a frequency line, (e) shows the microstructure of mild steel, and (f) shows the colour value variation in a line. 

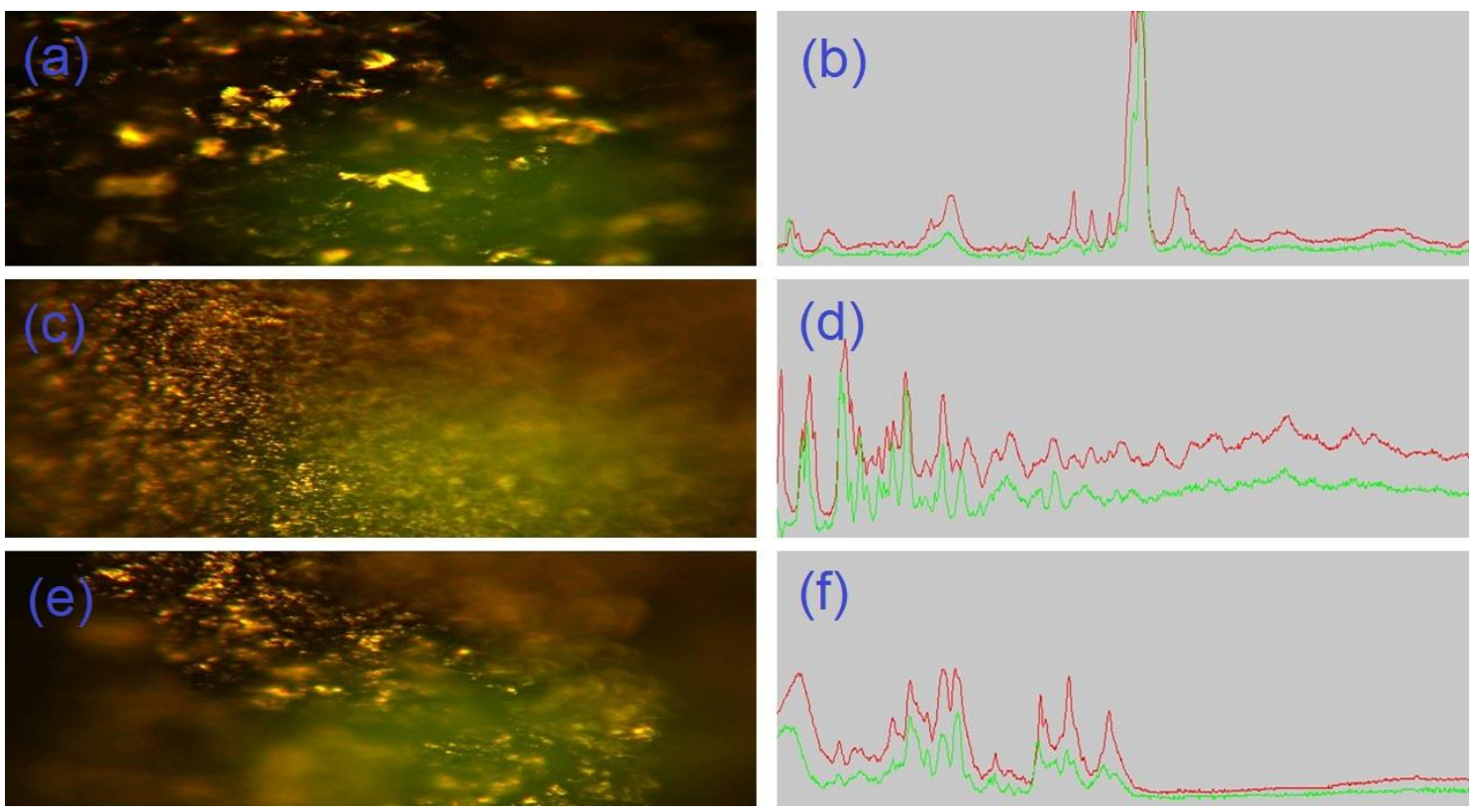

Figure 6. Typical microstructure of steel alloys after impact test at Mag. 20X: (a) shows the microstructure of carbon steel, (b) shows the colour value variation in a frequency line, (c) shows the microstructure of EN 8, (d) shows the colour value variation in a line, (e) shows the microstructure of mild steel and (f) shows the colour value variation in a frequency line.

\section{Tensile Properties}

Chen et al. [32] presented the tensile properties and microstructural behaviour of Hadfield steel by applying different strain rates during tensile test and found that by the addition of $\mathrm{N}+\mathrm{Cr}$ tensile strength increased considerably. Xiaoyun [33] investigated the mechanical properties and anti-corrosion behaviours of $\mathrm{Cr}$ and $\mathrm{Mn}$ addition to Fe-Mn-CAl-Cr-N steel have investigated and found that $\mathrm{Cr}$ addition increased ultimate tensile strength and yield strength but reduced percentage elongation. Furthermore, increased $\mathrm{Cr}$ content improved the corrosion resistance of the annealed steel. The variation of tensile strength and percentage elongation were analysed by experiment on the silicon content varied from 5, 7, 9, 12.5, and 14\% in five different aluminium alloys. The research found the significant increase in tensile and yield strengths of the material whereas a decrease in the ductility [34]. The mechanical properties of superplastic materials were investigated on superplastic $\mathrm{Al}-4 \cdot 5 \mathrm{Mg}$ alloy with different gauge lengths and elongation was found to increase to double when gauge length to width ratio reduced 4 to 1 [35]. The ultimate tensile and yield strengths of steel weld metals decreased but the impact strength of weld metals increased by $\mathrm{Ni}$ additions in a controlled manner with respect to $\mathrm{Mn}$. According to Scott et al., high-Mn austenitic steels are mostly used in automotive engineering applications due to its high strength and ductility [36]. Manganese combined with sulphur decreases the threat of solidification cracking [37]. The addition of chromium stabilises ferrite and increases tensile strength and hardness of steel as a solid solution strengthener but reduces toughness [15]. This paper investigated the microstructural behaviour and mechanical properties of three high strength low alloy sheets of steel used for armoured vehicle and found that the tensile strength of RHA had the highest value compared to other two AR500 and AISI 4340 sheets of steel [38]. The toughness of steel material depends on its chemical composition and microstructure [39]. The investigation of microstructure and mechanical properties of stainless steels having $0.004 \mathrm{wt} \% \mathrm{C}$ to $0.034 \mathrm{wt} \% \mathrm{C}$ was conducted and the martensitic texture was found to be 
influenced by carbon content [40]. The hardness and strength of the stainless steel increased by an increase in carbon content but at the same time decreased elongation and toughness[41]. The paper investigated the mechanical properties and microstructural behaviour by precipitation hardening effect on $\mathrm{Al}-\mathrm{Cu}-\mathrm{Zn}$ alloys and found that precipitation hardening increased the mechanical properties of aluminium alloys widely used in automobiles [42].

The tensile properties of three steel alloys at a strain rate of $1.3 \times 10^{-4} \mathrm{~s}^{-1}$ on UTM were tested and data generated for each alloy as shown in Tables 2, 3, and 4 for carbon, EN 8, and mild steels, respectively. The result of the tensile test is shown in Figure 3, where the plotted graph of stress-strain curves in software supports the UTM test while the generated data for carbon steel material are shown in Table 2. From the stress-strain graph, it was observed that carbon steel has Young's Modulus $=267 \mathrm{~N} / \mathrm{mm}^{2}$, upper yield stress $=333 \mathrm{~N} / \mathrm{mm}^{2}$, lower yield stress $=287 \mathrm{~N} / \mathrm{mm}^{2}$, maximum Stress $=420 \mathrm{~N} / \mathrm{mm}^{2}$, and fracture Stress $=336 \mathrm{~N} / \mathrm{mm}^{2}$. Like carbon steel, generated data for EN 8 and mild steel alloys are shown in Tables 3 and 4, respectively. Based on the test generated data shown in Tables 2-4, stress via elongation graph was plotted and is shown in Figure 7 for carbon, EN-8, and mild steel alloys. From Figure 7, it can be observed that the carbon steel has the upper/lower yield stress as 333/287 N/mm $\mathrm{mm}^{2}$, maximum stress as $420 \mathrm{~N} / \mathrm{mm}^{2}$, and the fracture stress as $336 \mathrm{~N} / \mathrm{mm}^{2}$. Similarly, for EN 8 steel, the yield stress was $635 \mathrm{~N} / \mathrm{mm}^{2}$, maximum stress $=882 \mathrm{~N} / \mathrm{mm}^{2}$ and fracture stress was $728 \mathrm{~N} / \mathrm{mm}^{2}$, whereas for mild steel the upper yield stress was $612 \mathrm{~N} / \mathrm{mm}^{2}$, lower yield stress $382 \mathrm{~N} / \mathrm{mm}^{2}$, maximum Stress $666 \mathrm{~N} / \mathrm{mm}^{2}$, and fracture stress $504 \mathrm{~N} / \mathrm{mm}^{2}$. From Figure 7, it was resolved that carbon steel alloy has high ductility, medium tensile strength, and hardness compared to EN 8 and mild steel alloys. Finally, Figure 8 shows that the stress-percentage elongation graph in software supports the UTM test and easy to observe the comparative test result mentioned above.
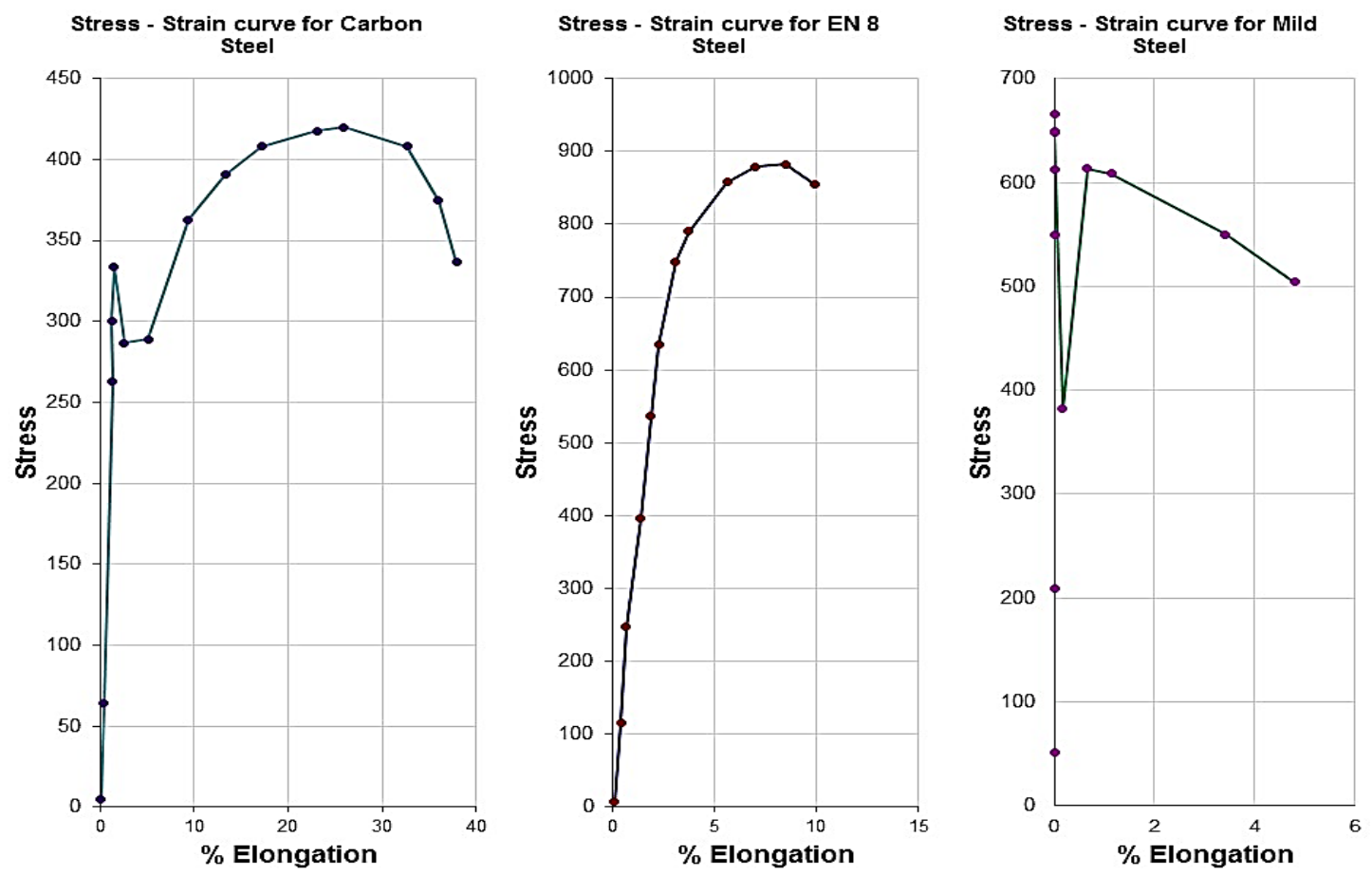

Figure 7. Typical stress-strain curves for carbon, EN 8, and mild steel alloys at a strain rate of $1.3 \times 10^{-4} \mathrm{~s}^{-1}$ 


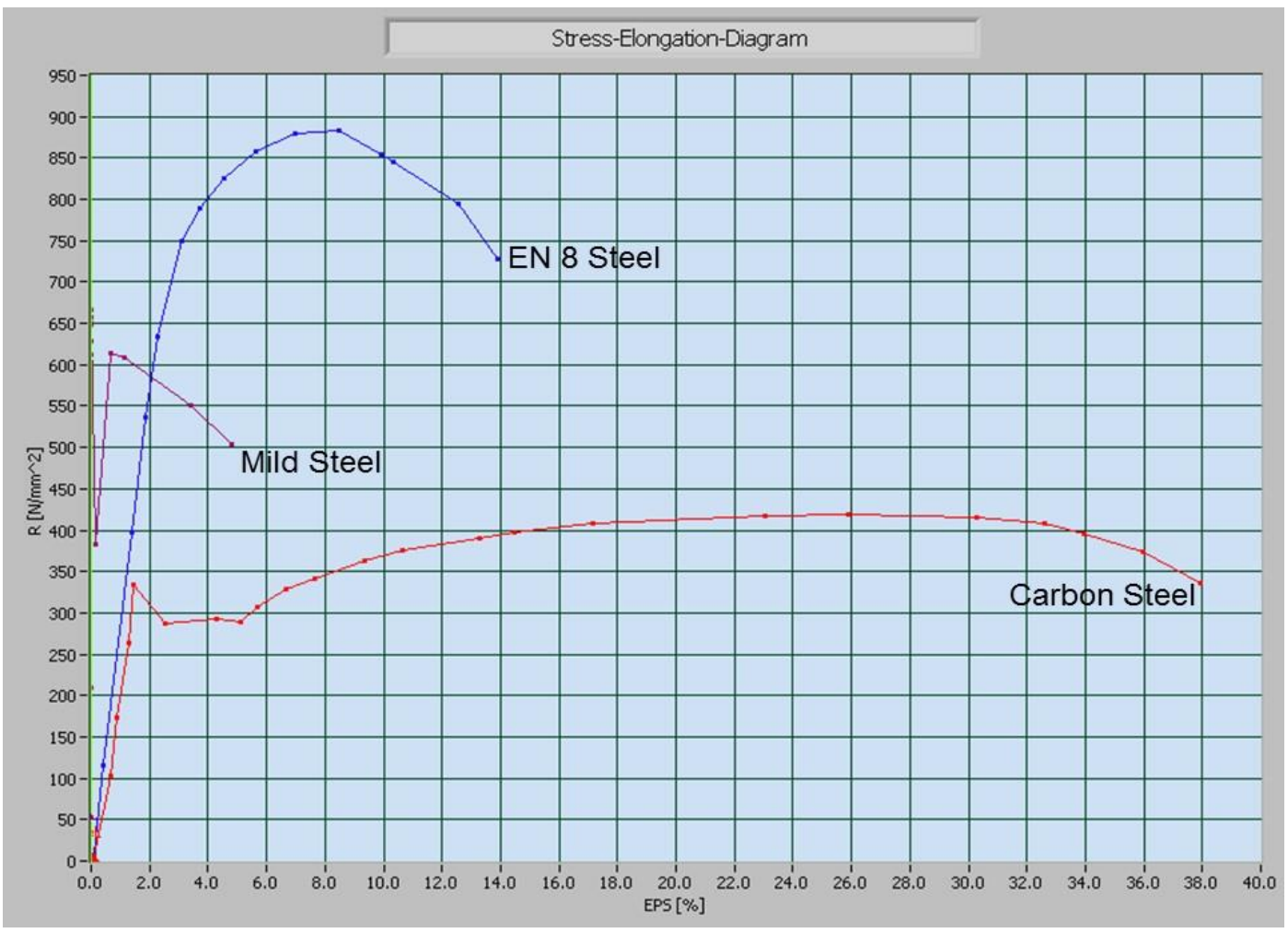

Figure 8. Comparative study of stress-elongation graph for three steel alloys.

Table 5. Mechanical properties of three steel alloys after all tests at room temperature.

\begin{tabular}{|c|c|c|c|c|}
\hline Material Properties & & Carbon Steel & EN-8 Steel & Mild Steel \\
\hline Young modulus & $\mathrm{N} / \mathrm{mm}^{2}$ & 263 & 537 & 549 \\
\hline Yield stress & $\mathrm{N} / \mathrm{mm}^{2}$ & $333 / 287$ & $635 / 0$ & $612 / 0$ \\
\hline Ultimate tensile strength & $\mathrm{N} / \mathrm{mm}^{2}$ & 420 & 882 & 743 \\
\hline Tensile Strength at Fracture & $\mathrm{N} / \mathrm{mm}^{2}$ & 336 & 728 & 505 \\
\hline Total Elongation & $\%$ & 38 & 14 & 5 \\
\hline Rockwell Hardness & HRB & 68.8 & 88.5 & 84.18 \\
\hline Impact Strength & $\mathrm{J} / \mathrm{cm}^{2}$ & 36.50 & 51.75 & 282.26 \\
\hline
\end{tabular}

From the stress-strain graph plotted in Figure 8, it can be observed that EN 8 steel alloy has high yield stress and tensile strength but lower ductility while mild steel alloy has a medium yield stress and tensile strength but medium ductility compared to carbon steel alloy. The addition of $\mathrm{Cr}$ and $\mathrm{Si}$ to iron forms a solid solution, which significantly increased the strength and corrosion resistance [32 - 34]. Specimen dimensions also influence the tensile strength and ductility of the material. As the gauge length increased, it reduced the effect of localised deformation at necking on total elongation; i.e., by increasing the gauge length percentage elongation of the specimen is further reduced [35]. The strain-hardening capacity of material also has impacts on the percentage elongation. During the test, the strain rate increased and significantly increased the flow stress. The addition of manganese gave strengthening effects by solid solution hardening and grain refinement during heating and cooling of the specimen by lowering the austenite to ferrite transformation temperature [33]. The toughness of steel was further increased by the grain 
refinement and also by the addition of nickel. The impact of $\mathrm{Cr}$ addition in two types of Co-Ni steels, one containing only $\mathrm{W}$ while others containing $\mathrm{W}$ and $\mathrm{Cr}$, were studied and cooperation yield strength and yield ratio (YS/UTS) were identified to decrease by the addition of $\mathrm{Cr}$ [42]. Table 5 shows the comparative observations of mechanical properties after the test results.

\section{CONCLUSIONS}

In this research, the mechanical properties and microstructural behaviour of three steel alloys were investigated using tensile, impact, and Rockwell hardness tests. The analysis of the result was conducted based on the variation and effect of the chemical composition of the alloying elements added to the steel on the mechanical behaviour. The experimental result showed that EN 8 steel had the highest ultimate tensile strength of $882 \mathrm{~N} / \mathrm{mm}^{2}$ followed by the mild steel of $666 \mathrm{~N} / \mathrm{mm}^{2}$ and carbon steel has the lowest value 420 $\mathrm{N} / \mathrm{mm}^{2}$. The percentage elongation of the steel alloys was compared as the highest value of elongation for carbon steel at $38 \%$ followed by EN 8 steel at $13.8 \%$ and the mild steel had the lowest elongation value at $4.8 \%$. The yield and ultimate tensile strengths of EN 8 steel were the highest due to more Si content in it compared to mild and carbon steels whereas percentage elongation decreased in EN 8 steel compared to carbon steel as more $\mathrm{Si}$ addition increased tensile strength but reduced ductility. Similarly, the composition of reduced $\mathrm{Mn}$ with increased $\mathrm{Ni}$ content increased the impact strength of mild steel compared to EN 8 steel. The increase in Mn content more than $0.23 \%$ reduced the elongation capacity of the EN 8 steel alloys and mild steel. The increased percentage weight content of $\mathrm{Cr}$ significantly improved tensile and yield strengths and reduced elongation of steel alloys. Further microstructural studies of steel alloys were investigated for different composition of alloying elements using an inverted microscope of the fracture surface of the specimens.

\section{ACKNOWLEDGEMENTS}

The author would like to thank the Department of Mechanical Engineering in Ibra college of Technology, Ibra for providing the laboratory facilities and supporting this selffinanced research work.

\section{REFERENCES}

[1] Thompson S, Colvin D, Krauss G. Austenite decomposition during continuous cooling of an hsla-80 plate steel. Metallurgical and Materials Transactions A. 1996;27:1557-71.

[2] Dieter GE, Schmidt LC. Engineering design: McGraw-Hill New York; 2013.

[3] Ghauri I, Afzal N, Shahzad M, Mubarik F. Tensile behavior of post-irradiation annealed cu-ni alloy. Radiation Effects \& Defects in Solids. 2011;166:228-32.

[4] Kumar K, Duesbery M, Louat N, Provenzano V, DiPietro M. Microporous finegrained copper: Structure and properties. Philosophical Magazine A. 2001;81:1023-40.

[5] Yoozbashi M, Yazdani S. Mechanical properties of nanostructured, low temperature bainitic steel designed using a thermodynamic model. Materials Science and Engineering: A. 2010;527:3200-5. 
[6] Bhattacharya B, Sharma A, Hazra S, Ray R. A study of microstructures and tensile properties of two Fe-Mn-Al-Si-C alloys. Metallurgical and Materials Transactions A. 2009;40:1190-202.

[7] Liao Y, Baker I. Microstructure and room-temperature mechanical properties of Fe 30Ni 20Mn 35Al 15. Materials characterization. 2008;59:1546-9.

[8] Huang C-F, Ou K-L, Chen C-S, Wang C-H. Research of phase transformation on $\mathrm{Fe}-8.7 \mathrm{Al}-28.3 \mathrm{Mn}-1 \mathrm{C}-5.5 \mathrm{Cr}$ alloy. Journal of Alloys and Compounds. 2009;488:246-9.

[9] Zhang L, Meng L. Microstructure and properties of $\mathrm{Cu}-\mathrm{Ag}, \mathrm{Cu}-\mathrm{Ag}-\mathrm{Cr}$ and $\mathrm{Cu}-$ Ag-Cr-Re alloys. Materials Science and Technology. 2003;19:75-9.

[10] Nafsin N, Rashed H. Effects of copper and magnesium on phase formation modeling and mechanical behavior in $\mathrm{Al}-\mathrm{Cu}-\mathrm{Mg}$ alloys. International Journal of Automotive and Mechanical Engineering. 2013;8:1151-61.

[11] Arlazarov A, Gouné M, Bouaziz O, Hazotte A, Petitgand G, Barges P. Evolution of microstructure and mechanical properties of medium Mn steels during double annealing. Materials Science and Engineering: A. 2012;542:31-9.

[12] Salleh Z, Yusop M, Rosdi M. Mechanical properties of activated carbon (AC) coir fibers reinforced with epoxy resin. Journal of Mechanical Engineering and Sciences. 2013;5:631-8.

[13] Hariprasad T, Dharmalingam G, Praveen Raj P. Study of mechanical properties of banana-coir hybrid composite using experimental and fem techniques. Journal of Mechanical Engineering and Sciences. 2013;4:518-31.

[14] Lampman S. Weld integrity and performance: A source book adapted from asm international handbooks, conference proceedings, and technical books: ASM International; 1997.

[15] Evans GM, Bailey N. Metallurgy of basic weld metal: Elsevier; 1997.

[16] Roy A, Kumar P, Maitra D. The effect of silicon content on impact toughness of T91 grade steels. Journal of Materials Engineering and Performance. 2009;18:205-10.

[17] Higgins RA. The properties of engineering materials: Industrial Press Inc.; 1994.

[18] CHI H-x, Jian Z, YONG Q-1. Microstructure and mechanical properties of martensitic stainless steel $6 \mathrm{cCr} 15 \mathrm{MoVn}$. Journal of Iron and Steel Research, International. 2012;19:56-61.

[19] Zhong P. Microstructure and mechanical properties in isothermal tempering of high Co-Ni secondary hardening ultrahigh strength steel. Journal of Iron and Steel Research, International. 2007;14:292-5.

[20] Mathew M, Rajendrakumar P. Optimization of process parameters of borocarburized low carbon steel for tensile strength by taquchi method with grey relational analysis. Materials \& Design. 2011;32:3637-44.

[21] Jha SK, Balakumar D. Experimental analysis of mechanical properties on AA6060 and 6061 aluminum alloys. International Journal of Engineering Research and Applications. 2015;5:47-53.

[22] Charde N. Microstructure and fatigue properties of dissimilar spot welded joints of AISI 304 and AISI 1008. International Journal of Automotive and Mechanical Engineering. 2013;7:882-99.

[23] Jha SK, Balakumar D, Paluchamy R. Experimental analysis of microstructure and mechanical properties of copper and brass based alloys. International Journal of Automotive and Mechanical Engineering. 2015;11:2317. 
[24] Kako K, Kawakami E, Ohta J, Mayuzumi M. Effects of various alloying elements on tensile properties of high-purity $\mathrm{Fe}-18 \mathrm{Cr}-(14-16) \mathrm{Ni}$ alloys at room temperature. Materials Transactions. 2002;43:155-62.

[25] Park D, Lee J, Lee Y, Park K, Nam W. The effects of alloying elements on tensile strength and the occurrence of delamination in cold-drawn hyper-eutectoid steel wires. Metals and Materials International. 2009;15:197-202.

[26] Zhu T, Fu P, Peng L, Hu X, Zhu S, Ding W. Effects of mn addition on the microstructure and mechanical properties of cast $\mathrm{Mg}-9 \mathrm{Al}-2 \mathrm{Sn}$ (wt.\%) alloy. Journal of Magnesium and Alloys. 2014;2:27-35.

[27] Zhao Y, Guo Y, Wei Q, Dangelewicz A, Xu C, Zhu Y, et al. Influence of specimen dimensions on the tensile behavior of ultrafine-grained $\mathrm{Cu}$. Scripta Materialia. 2008;59:627-30.

[28] Sergueeva A, Zhou J, Meacham B, Branagan D. Gage length and sample size effect on measured properties during tensile testing. Materials Science and Engineering: A. 2009;526:79-83.

[29] Klein M, Hadrboletz A, Weiss B, Khatibi G. The 'size effect'on the stress-strain, fatigue and fracture properties of thin metallic foils. Materials Science and Engineering: A. 2001;319:924-8.

[30] Mamedov A, Mamedov V. Microstructure, mechanical properties and tribological behaviour of $\mathrm{Pm} \mathrm{Fe}-\mathrm{Cu}-\mathrm{Zn}$ alloys containing solid lubricants. Powder metallurgy. 2003;46:311-8.

[31] Fang X, Fan Z, Ralph B, Evans P, Underhill R. Effects of tempering temperature on tensile and hole expansion properties of a C-Mn steel. Journal of Materials Processing Technology. 2003;132:215-8.

[32] Chen C, Zhang F, Wang F, Liu H, Yu B. Effect of n+ Cr alloying on the microstructures and tensile properties of hadfield steel. Materials Science and Engineering: A. 2017;679:95-103.

[33] Yuan X, Zhao Y, Li X, Chen L. Effect of $\mathrm{Cr}$ on mechanical properties and corrosion behaviors of Fe-Mn-C-Al-Cr-N twip steels. Journal of Materials Science \& Technology. 2017.

[34] Kalhapure MG, Dighe PM. Impact of silicon content on mechanical properties of aluminum alloys. International Journal of Scientifc Research. 2015;4:38-40.

[35] Bate P, Ridley N, Sotoudeh K. Effect of gauge length in superplastic tensile tests. Materials Science and Technology. 2008;24:1265-70.

[36] Keehan E, Karlsson L, Andrén H-O, Bhadeshia H. Influence of carbon, manganese and nickel on microstructure and properties of strong steel weld metals: Part 3-increased strength resulting from carbon additions. Science and Technology of Welding and Joining. 2006;11:19-24.

[37] Scott C, Allain S, Faral M, Guelton N. The development of a new fe-mn-c austenitic steel for automotive applications. Revue de Métallurgie-International Journal of Metallurgy. 2006;103:293-302.

[38] Hertzberg RW. Deformation and fracture mechanics of engineering materials. 1989.

[39] Jamil W, Aripin M, Sajuri Z, Abdullah S, Omar M, Abdullah M, et al. Mechanical properties and microstructures of steel panels for laminated composites in armoured vehicles. International Journal of Automotive \& Mechanical Engineering. 2017; 14(1):3824-36.

[40] Zheng H, Ye X, Li J, Jiang L, Liu Z, Wang G, et al. Effect of carbon content on microstructure and mechanical properties of hot-rolled low carbon $12 \mathrm{cr}-\mathrm{ni}$ stainless steel. Materials Science and Engineering: A. 2010;527:7407-12. 
[41] Odusote J, Adeleke A, Ajayi P. Mechanical properties and microstructure of precipitation-hardened al-cu-zn alloys. International Journal of Automotive and Mechanical Engineering. 2015;12:3033.

[42] Sim H, Cho K, Lee K, Yang H, Kwon H. Tensile properties in w-containing high co-ni steels. Materials Science and Engineering: A. 2007;449:1143-6. 